\title{
PRIORIDADES DE MANEJO PARA A ARBORIZAÇÃO VIÁRIA DA ESTÂNCIA DE ÁGUAS DE SÃO PEDRO-SP, POR SETORES
}

Silvana Bortoleto ${ }^{1}$, Demóstenes Ferreira da Silva Filho ${ }^{2}$, Ana Maria Liner Pereira Lima ${ }^{3}$

\section{RESUMO}

A arborização urbana exige um planejamento criterioso e um manejo adequado para proporcionar os benefícios. Entretanto, muitas cidades brasileiras não possuem tal planejamento, na medida em que muitos projetos baseiam-se em métodos puramente empíricos. O presente trabalho é referente à obtenção de dados para subsidiar as prioridades de manejo para a arborização viária da Estância de Águas de São Pedro, através da análise do levantamento quali-quantitativo, que foi baseado em um banco de dados relacional. Para isso, foi realizado um censo dos indivíduos das vias públicas e, para melhor estruturar as análises e priorizar o manejo, a Estância foi divida em 6 setores. Podendo-se observar a necessidade de várias práticas de manejo em todos os setores da Estância de Águas de São Pedro; concluindo que algumas ações urgentes são requeridas, como por exemplo: a)adequação das mudas a serem plantadas; b) prioridades de manejo e intervenções focadas nos setores 1 e 3; c) podas criteriosas de condução ou troca de fiação no setor 5; d) ampliação de canteiros, priorizando setor 1; e) recomendação de canteiros de 1 a $2 \mathrm{~m}^{2}$ por árvore ou o estabelecimento de faixas permeáveis (verdes) na extensão da calçada, por todo o município.

Palavras-chave: Arborização viária, Manejo, Malha viária

\footnotetext{
1. Engenheira Agrônoma, doutoranda ESALQ-USP, Piracicaba-SP, silvana@esalq.usp.br

2. Engenheiro Agrônomo, professor Engenharia Florestal - ESALQ-USP, Piracicaba-SP, dfsilva@esalq.usp.br

3. Engenheira Agrônoma, professora Produção Vegetal - ESALQ-USP, Piracicaba-SP, amlplima@esalq.usp.br
} 


\title{
PRIORITIES OF HANDLING FOR THE STREET ARBORIZATION OF THE ÁGUAS DE SÃO PEDRO-BRASIL, FOR SECTIONS
}

\begin{abstract}
The urban arborization demands a sensible planning and an adequate handling to provide the benefits. However, many Brazilian cities do not have such planning, since many projects are purely based on empirical methods. The present refers to data collection in order to subsidize handling priorities for the street arborization of the Águas de São Pedro-Brazil, through quali-quantitative survey analysis, based on a relational data base. For this purpose, was carried out a census of the individuals in public ways and, to improve the analysis structure and prioritize the handling, the city was divided in 6 sections. It was observed the necessity of several practical of handling in all the sectors of Águas de São Pedro-Brazil; concluding some urgent actions are required as, for example: a) adequacy of the seedling to be planted; b) priorities in handling and interventions focused in sections 1 and 3; c) sensible conduction pruning or wiring change in section 5 ; d) increasing of seedbeds, prioritizing section 1 ; e) recommendation of 1 or $2 \mathrm{~m}^{2}$ seedbeds per tree or the establishment of permeable bands (green) in sidewalk, all over the city.
\end{abstract}

Key-words: Street arborization, Handling, road Mesh 


\section{INTRODUÇÃO}

A arborização urbana, para propiciar benefícios à população, exige um planejamento criterioso e um manejo adequado. A avaliação da cobertura de árvores na cidade pode ajudar no planejamento da vegetação urbana e na sua administração, na medida em que revela características da vegetação (Nowak et al., 1996; Silva, 2000; Meneguetti, 2003).

Entretanto, muitas cidades brasileiras não possuem um planejamento adequado de arborização urbana, na medida em que muitos projetos baseiam-se em métodos puramente empíricos, desprovidos de um conhecimento real do assunto. Como conseqüência dessa inadequação, a arborização empreendida mostra-se ineficaz, pois os benefícios - que esta poderia, potencialmente, proporcionar à população - não são observados.

A arborização urbana pressupõe as atividades de planejamento, implantação e manutenção sob o poder público. Entretanto, normalmente, estas etapas da arborização são preteridas em função da implantação de redes elétricas, de redes de saneamento, de calçadas, de ruas, etc. O planejamento da arborização deve ser bem acompanhado para correção imediata de eventuais falhas e deve atender aos objetivos pré-determinados, além de ser continuamente avaliado e controlado (Kirchner et al., 1990).

Os planos de arborização devem ser o resultado da apreciação de vários elementos físicos e ambientais. É certo que a simples presença de árvores ao longo das vias não qualifica a arborização, pois são comuns altas populações que incluem árvores quebradas, disformes, doentes e mortas (Santos \& Teixeira, 2001).

A definição de metodologias para avaliação e diagnóstico da arborização depende de objetivos específicos. O processo de monitoramento, com a realização de avaliações específicas ou inventários, envolve etapas de avaliação de parâmetros, realização de inventário do patrimônio arbóreo e análise quali-quantitativo dos dados (Milano \& Dalcin, 2000).

Os objetivos da realização de um inventário arbóreo podem ser assim resumidos: a) preparar um programa de gerenciamento das árvores; b) identificar necessidades de manejo; c) definir prioridades nas intervenções; d) localizar áreas para o plantio; e) localizar árvores com necessidade de remoção; f) funcionar como instrumento de persuasão; entre outros (Motta, 2000).

A partir da premissa de que o planejamento da arborização é de essencial importância para seu êxito, o presente trabalho é referente à obtenção de dados para subsidiar as prioridades de manejo para a arborização viária da Estância de Águas de São Pedro através da análise do levantamento quali-quantitativo realizado na Estância, onde o inventário baseou-se em um banco de dados relacional. 


\section{MATERIAIS E MÉTODOS}

\section{Local de Estudo}

O estudo foi realizado na Estância de Águas de São Pedro, município do Estado de São Paulo. Sua área total perfaz $3,9 \mathrm{~km} 2$ e sua localização apresenta as seguintes referências: entre $22^{\circ} 35^{\prime} 58^{\prime \prime}$ Latitude Sul e 47052'34" Longitude Oeste, fazendo divisa com o município de São Pedro em todo o seu perímetro. A Estância apresenta altitude de $470 \mathrm{~m}$, com temperatura média anual de $27,2^{\circ} \mathrm{C}$ e índice pluviométrico de $500 \mathrm{~mm} / \mathrm{ano}$ (Águas de São Pedro, 2004).

Possui uma população urbana de 1.845 pessoas (Censo 2000-IBGE). A taxa de crescimento demográfico é de 4,06\% ao ano e a densidade demográfica é de 473,08 habitantes/km2. A taxa de urbanização é de 100\%, não possuindo área rural. A economia local é alicerçada no turismo, que é a atividade preponderante no município, muito procurado principalmente por suas águas medicinais (Águas de São Pedro, 2004).

\section{Material de Campo}

Seguem o instrumento e o material utilizado, com as respectivas finalidades:

- $\quad$ caderno de planilhas para as anotações qualitativas e quantitativas;

- $\quad$ hipsômetro Blume-Leiss: determinação da altura dos indivíduos.

\section{Levantamento de Informações}

Foi realizado um censo dos indivíduos das vias públicas. Para melhor estruturar as análises e priorizar o manejo, a Estância foi divida em 6 setores (Figura 1). 


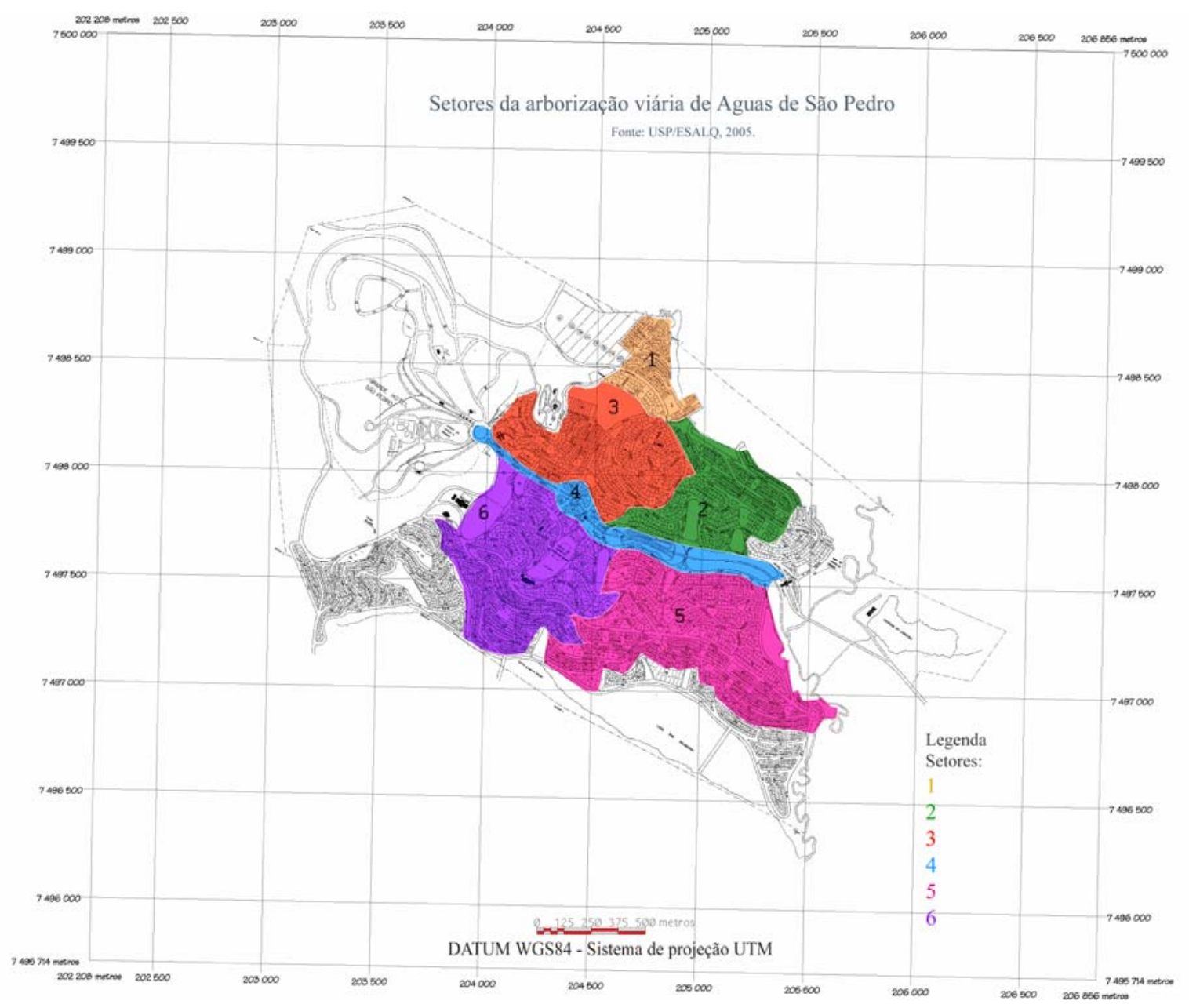

Figura 1. Mapa da Estância de Águas de São Pedro dividida por 6 setores

\section{Análise dos Dados}

Os dados provenientes do censo da população arbórea viária foram tabulados em um banco de dados do Microsoft Access elaborado por Silva Filho (2002), onde foram realizadas consultas de referência cruzada entre as variáveis coletadas e os setores.

\section{RESULTADOS E DISCUSSÕES}

Na Tabela 1 pode-se verificar que os indivíduos da arborização viária apresenta baixa porcentagem referente a lesões (leve, média e grave), isso se dá pelo baixo índice de podas realizadas no município, e estas, quando realizadas, quantificam as lesões graves, por serem drásticas e proporcionarem a presença de cupins; nisso o setor 3 se destaca, devendo ser prioridade em podas de limpeza e a realização de controle biológico para redução de infestações de brocas e cupins.

Em relação aos indivíduos que se apresentam com desequilíbrio (assimetria) em seu caule, copa, ou ambos, observa-se alta porcentagem (60\% no geral de toda a 
arborização), indicando a falta de condução dos indivíduos jovens em todos os setores e inadequação das mudas utilizadas nos plantios de todo o município (Tabela 1).

Observa-se na Tabela 1 que 78\%, de toda a arborização viária foi classificada em condições gerais boa e ótima, sendo que $22 \%$ de toda a arborização encontra-se em condição regular, péssima ou morta.

Os setores 1 e 3 são possuidores das maiores quantidade de indivíduos em condição regular, péssima ou morta, com $24 \%$ e $29 \%$, respectivamente. São, portanto, os setores com indicações de prioridades de manejo (Tabela 1).

A média geral de indivíduos em condição péssima (final de declínio) ou morta, em toda a Estância de Águas de São Pedro é de 5,47\%. Há preocupação com a substituição dos indivíduos mortos e alguns péssimos, devendo-se priorizar os setores 1 e 3 (Tabela 2) e ainda o tratamento dos indivíduos em estado regular e péssimo, com prioridade no setor 3 (Tabela 1).

Tabela 1. Porcentagem de indivíduos apresentando condição geral ótima, boa, regular, péssima, morta, lesão leve, média, grave, broca, cupim e desequilibrados, por setor da arborização viária da Estância de Águas de São Pedro.

\begin{tabular}{cccccccccccc}
\hline \multicolumn{1}{c}{ Setor Ótima } & \multicolumn{1}{c}{ Boa } & \multicolumn{1}{c}{ Regular Péssima } & Morta & leve & média & grave & Broca & Cupim Desequilibrados \\
\hline 1 & 19,00 & 57,00 & 16,00 & 2,50 & 5,50 & 0,00 & 0,00 & 0,51 & 0,00 & 0,51 & 49,24 \\
2 & 21,00 & 60,26 & 15,60 & 2,10 & 1,05 & 0,13 & 2,49 & 0,79 & 1,31 & 2,49 & 58,85 \\
3 & 13,00 & 58,00 & 22,20 & 5,40 & 1,40 & 1,05 & 2,27 & 2,62 & 0,00 & 5,94 & 67,48 \\
4 & 20,00 & 60,00 & 14,00 & 4,50 & 1,50 & 1,91 & 0,00 & 0,00 & 0,48 & 1,44 & 57,89 \\
5 & 23,48 & 59,53 & 11,69 & 4,91 & 0,39 & 0,20 & 1,77 & 2,75 & 0,98 & 4,13 & 58,45 \\
6 & 20,40 & 58,50 & 17,56 & 3,09 & 0,45 & 1,01 & 1,23 & 2,35 & 0,89 & 3,24 & 69,57 \\
\hline
\end{tabular}

Tabela 2. Porcentagem de substituição de indivíduos por setor da arborização viária da Estância de Águas de São Pedro.

\begin{tabular}{cc}
\hline Setor & Substituição \\
\hline 1 & 9,64 \\
2 & 1,05 \\
3 & 4,2 \\
4 & 1,44 \\
5 & 2,16 \\
6 & 2,35 \\
\hline
\end{tabular}


Para atender aos ajustes mencionados acima, quanto à substituição de indivíduos, tem-se a indicação de substituição de 97 indivíduos, destes, parte são árvores em fase final de declínio ou indivíduos mortos, e parte são arbustos, plantados em locais onde as substituições por árvores com função ambiental é propícia (Tabela 3).

Além disso, há a indicação de 202 novos plantios em covas vazias e já prontas nas ruas da cidade, há também a indicação da realização de novas covas nas vias onde a densidade de árvores estiver abaixo da requerida.

Tabela 3. Distribuição das espécies com recomendação de substituição na arborização viária da Estância Turística de Águas de São Pedro-SP

\begin{tabular}{ccc}
\hline Nome Comum & Nome Científico & Freqüência (\%) \\
\hline Mortas & - & 34,02 \\
Sibipiruna & Caesalpinia peltophoroides Benth. & 18,56 \\
Primavera & Bougainvillea spectabilis Willd & 5,15 \\
Pingo-de-ouro & Duranta repens L. & 5,15 \\
Azaléia & Rhododendron simsii Planch. & 4,12 \\
Flamboyant & Delonix regia (Bojer ex Hook.) Raf. & 4,12 \\
Jacarandá-mimoso & Jacaranda mimosaefolia D. Don & 3,09 \\
Mangueira & Mangifera indica L. & 3,09 \\
Tipuana & Tipuana tipu (Benth.) Kuntze & 3,09 \\
Hibisco & Hibiscus rosa-sinensis L. & 2,06 \\
Lanterna-japonesa & Koelreuteria elegans (Seem.) & 2,06 \\
Outras & & 15,49 \\
\hline
\end{tabular}

Observa-se na Tabela 4, a porcentagem de indivíduos com altura superior e inferior a $2 \mathrm{~m}$ em cada setor e a preocupação na renovação da população arbórea, ao se inserir árvores jovens ao invés de arbustos. Na Tabela 5, nota-se o número de espécies encontradas em cada setor; verifica-se que a diversidade (riqueza de espécies) tende a se manter e ser maior com indivíduos acima de 2 metros de altura; enquanto que nas espécies inferiores a $2 \mathrm{~m}$, ocorre um menor número de espécies e de riqueza, com maior variação, mostrando a menor quantidade de espécies com indivíduos jovens, reforçando a necessidade de adequação de diversidade e de renovação da população. 
Tabela 4. Porcentagem de indivíduos com altura superior e inferior a $2 \mathrm{~m}$

\begin{tabular}{ccc}
\hline Setor & $<2 \mathrm{~m}$ & $>2 \mathrm{~m}$ \\
\hline 1 & 12,63 & 87,37 \\
2 & 23,36 & 76,64 \\
3 & 13,81 & 86,19 \\
4 & 10,95 & 89,05 \\
5 & 22,62 & 77,38 \\
6 & 19,44 & 80,56 \\
\hline
\end{tabular}

Tabela 5. Quantidade de espécies encontradas e índice de Riqueza de Odum por setor, com altura inferior a $2 \mathrm{~m}$ e superior a $2 \mathrm{~m}$ por setor da arborização viária da Estância de Águas de São Pedro

\begin{tabular}{cccccc}
\hline Setor & $\begin{array}{c}\text { Espécies } \\
\text { encontradas }\end{array}$ & $\begin{array}{c}\text { Espécies com } \\
\text { altura }<2 \mathrm{~m}\end{array}$ & $\begin{array}{c}\text { Riqueza de } \\
\text { espécies }<2 \mathrm{~m}\end{array}$ & $\begin{array}{c}\text { Espécies com } \\
\text { altura }>2 \mathrm{~m}\end{array}$ & $\begin{array}{c}\text { Riqueza de } \\
\text { espécies }>2 \mathrm{~m}\end{array}$ \\
\hline 1 & 50 & 15 & 4,41 & 46 & 8,73 \\
2 & 93 & 52 & 9,84 & 77 & 11,93 \\
3 & 77 & 40 & 8,93 & 67 & 10,64 \\
4 & 39 & 16 & 4,85 & 33 & 6,12 \\
5 & 109 & 54 & 9,75 & 94 & 13,95 \\
6 & 96 & 48 & 9,12 & 88 & 13,22 \\
\hline
\end{tabular}

Em relação aos equipamentos urbanos, pode-se verificar a alta pressão ocorrida sobre a arborização, por meio da intensidade de contatos entre os mesmos; contatos esses, com a fiação elétrica e de telefone, postes de fiação, postes de iluminação, muro e sinalização (placas e semáforos) (Tabela 6).

O setor 4 apresentou menor pressão por se tratar do canteiro central de avenida; os demais setores apresentaram elevada pressão pelas árvores estarem localizadas nas calçadas. Os setores 1 e 2 apresentaram maior contato, sendo o contato atual com fiação, poste e muro os fatores determinantes. Deve-se então, priorizar propostas de redução dos contatos atuais, por meio de trocas de fiação, deslocamento de postes, rebaixamento de iluminação, podas leves, melhoria dos critérios de plantio (definição da localização), procurando preservar a arborização existente. O setor 1 possui a maior porcentagem de contato atual com a fiação, devendo ser priorizada nas intervenções; o setor 5 possui a maior porcentagem de contato potencial, indicando a possibilidade de podas criteriosas de condução ou troca de fiação. A sinalização não é conflitante com a arborização, podendo ser classificada como adequada (Tabela 6). 
Tabela 6. Porcentagem de contatos atuais (a) e potenciais (p) com os elementos urbanos (fiação, iluminação, posteamento, muro e sinalização), por setor da arborização viária da Estância de Águas de São Pedro, e o seu total

Fiação Fiação lluminação lluminação Poste Poste Muro Muro Sinalização Sinalização Total

\begin{tabular}{cccccccccccc} 
Setor & $\mathrm{p}$ & $\mathrm{a}$ & $\mathrm{p}$ & $\mathrm{a}$ & $\mathrm{p}$ & $\mathrm{a}$ & $\mathrm{p}$ & $\mathrm{a}$ & $\mathrm{p}$ & $\mathrm{a}$ & contato \\
\hline 1 & 30,96 & 23,86 & 1,52 & 7,61 & 3,55 & 9,14 & 1,52 & 4,06 & 0,00 & 1,02 & 83,25 \\
2 & 40,10 & 21,23 & 3,93 & 1,31 & 7,73 & 4,59 & 1,97 & 3,54 & 0,13 & 0,13 & 84,67 \\
3 & 36,36 & 22,03 & 3,32 & 1,22 & 8,22 & 2,62 & 1,75 & 2,97 & 0,00 & 0,00 & 78,50 \\
4 & 24,40 & 8,61 & 1,44 & 1,44 & 2,87 & 0,96 & 4,78 & 4,31 & 0,00 & 0,48 & 49,28 \\
5 & 49,21 & 11,39 & 2,55 & 0,88 & 7,86 & 3,14 & 0,69 & 1,18 & 0,10 & 0,20 & 77,21 \\
6 & 33,33 & 15,44 & 3,80 & 0,78 & 6,71 & 5,48 & 2,68 & 2,35 & 0,34 & 0,11 & 71,03 \\
\hline
\end{tabular}

Houve relação entre a ausência de áreas livre para as raízes, afloramento e indicação de ampliação de canteiro. Isso indica que a proporção de área livre foi determinante nos problemas de afloramento de raízes, servindo de indicação para os novos plantios, em medidas de adequação, sendo recomendado de 1 a $2 \mathrm{~m}^{2}$ de canteiro por árvore ou o estabelecimento de faixas permeáveis (verdes) na extensão da calçada. No setor 6 , apesar do elevado afloramento, não ocorreram danos a calçada que justifiquem intervenções, já os setores 1 e 3 devem ser priorizados no que se trata da ampliação de canteiros (Tabela 7).

Tabela 7. Porcentagem de indivíduos apresentando o colo pavimentado, afloramento de raízes na calçada e indicação de ampliação de canteiro por setor da arborização viária da Estância de Águas de São Pedro

\begin{tabular}{cccc}
\hline Setor & Colo pavimentado & Afloramento & Ampliação \\
\hline 1 & 9,64 & 17,26 & 3,05 \\
2 & 1,57 & 14,02 & 2,10 \\
3 & 3,67 & 18,01 & 2,62 \\
4 & 0,48 & 9,57 & 0,48 \\
5 & 0,49 & 10,51 & 0,49 \\
6 & 1,68 & 18,01 & 1,01 \\
\hline
\end{tabular}

Para a melhor adequação e planejamento da arborização no município e para o poder público poder exercer uma política na arborização é imprescindível o estabelecimento de um viveiro de mudas, onde ocorreria à definição correta de espécies, a padronização e o 
monitoramento das mesmas, o planejamento de coleta de sementes e as trocas de mudas e sementes com outros viveiros (municípios) para a diversificação genética.

Para a coleta de sementes no município, indica-se o mês de julho, as espécies com frutificação e as espécies com floração, para os próximos meses (Tabela 8).

A grande quantidade de indivíduos com folha indicam que estes são em sua maioria de folhagem permanente, não apresentando repouso de inverno e que para essas espécies a melhor época para a poda é a compreendida entre o final do florescimento e o início da frutificação. Já as espécies com repouso real, ou seja, espécies caducifólias que entram em repouso após a perda das folhas, a melhor época para a poda é compreendida entre o início do período vegetativo e o início do florescimento. Enquanto que as espécies com repouso falso, espécies caducifólias que não entram em repouso após a perda das folhas, a melhor época para a poda é a compreendida entre o final do florescimento e o início do período vegetativo (Manual técnico de poda de árvores, 2004).

Tabela 8. Porcentagem de indivíduos apresentando frutos, flores e folhas por setor da arborização viária da Estância de Águas de São Pedro

\begin{tabular}{cccc}
\hline Setor & Fruto & Flor & Folha \\
\hline 1 & 22,34 & 15,23 & 98,48 \\
2 & 24,25 & 14,68 & 99,34 \\
3 & 23,78 & 10,14 & 99,83 \\
4 & 34,45 & 12,44 & 95,22 \\
5 & 20,92 & 14,24 & 96,66 \\
6 & 25,06 & 19,24 & 98,32 \\
\hline
\end{tabular}

\section{CONCLUSÕES}

No geral a arborização está em bom estado, porém constata-se a falta de planejamento e manejo, indicando a necessidade de ações urgentes para modificações dessa situação, no qual a administração pública municipal deverá exercer políticas públicas, a qual é indefinida e necessita de:

- adequação em todos os setores das mudas a serem plantadas e de planejamento prévio;

- prioridades de manejo e intervenções focadas nos setores 1 e 3;

- podas criteriosas de condução ou troca de fiação no setor 5;

- prioridade do tratamento de brocas e cupins no setor 3;

- ampliação de canteiros, priorizando setor 1; 
- recomendação de canteiros de 1 a $2 \mathrm{~m}^{2}$ de por árvore ou o estabelecimento de faixas permeáveis (verdes) na extensão da calçada;

- coleta de sementes e as trocas de mudas e sementes com outros viveiros;

- estabelecimento de um viveiro de mudas (para padronização e o monitoramento das mesmas).

\section{REFERÊNCIAS BIBLIOGRÁFICAS}

ÁGUAS DE SÃO PEDRO. www.aguasdesaopedro.sp.gov.br (15 mar. 2004).

IBGE - Instituto Brasileiro de Geografia e Estatística, STATCART - Base de informações por setorcensitário, Estância de Águas de São Pedro, SP - Censo Demográfico 2000. Rio de Janeiro, RJ, 2002. 1 CD-ROM.

KIRCHNER, F.F.; DETZEL, V.A.; MITISHITA, E.A. Mapeamento da vegetação urbana. In: ENCONTRO NACIONAL SOBRE ARBORIZAÇÃO URBANA, 3., Curitiba, 1990. Curitiba: FUPEF, 1990. p.72-85.

MANUAL TÉCNICO DE PODA DE ÁRVORES. Secretaria Municipal do Verde e Meio Ambiente. Departamento de parques e áreas verdes. São Paulo, 2004.

MENEGUETTI, G.I.P. Estudo de dois métodos de amostragem para inventário da arborização de ruas dos bairros da orla marítima do município de Santos-SP. Piracicaba, 2003. 100p. Dissertação (Mestrado) - Escola Superior de Agricultura "Luiz de Queiroz", Universidade de São Paulo.

MILANO, M.S.; DALCIN, E. Arborização de vias públicas. Rio de Janeiro: Light, 2000. $206 p$.

MOTTA, G.L.O. Inventário da arborização urbana. Ação Ambiental: Arborização Urbana, v.2, n.9, p.11-13, 2000.

NOWAK, D.J.; ROWNTREE, R.A.; MCPHERSON, E.G.; SISINNI, S.M.; KERKMANN, E.R.; STEVENS, J.C. Measuring and analyzing urban tree cover. Landscape and Urban Planning. v.36, p.49-57, 1996. 
SANTOS, N.R.Z dos; TEIXEIRA, I.F. Arborização de vias públicas: ambiente x vegetação. Santa Cruz do Sul: Instituto Souza Cruz, 2001. 135p.

SILVA, A.G. da. Avaliação da arborização no perímetro urbano de Cajuri-MG, pelo método do quadro sintético. Viçosa, 2000. 150p. Dissertação (Mestrado) - Universidade Federal de Viçosa. 